\title{
The comparison of sedation quality, side effect and recovery profiles on different dosage of remifentanil patient- controlled sedation during breast biopsy surgery
}

\author{
Jin-Deok Joo, Jang Hyeok In, Dae-Woo Kim, Hong Soo Jung, Jae Hyeok Kang, Je Hwa Yeom, and \\ Jin Woo Choi
}

Department of Anesthesiology and Pain Medicine, The Catholic University of Korea, Suwon, Korea

Background: The patient-controlled sedation (PCS) allows for rapid individualized titration of sedative drugs. Propofol has been the most widely used IV adjuvant, during the monitored anesthesia care (MAC). This study was designed to compare the sedation quality, side effect and recovery of the propofol alone, and propofol-remifentanil combination, using PCS for breast biopsy.

Methods: Seventy five outpatients, undergoing breast biopsy procedures with local anesthesia, were randomly assigned to receive propofol alone (group P), propofol- $25 \mathrm{ug} / \mathrm{ml}$ of remifentanil (group PR25), and propofol-50 ug/ml of remifentanil (group PR50), using PCS. Pain visual analogue scores (VAS) and digit symbol substitution test (DSST), Vital signs, bi-spectral index (BIS) and observer assessment of alertness and sedation (OAA/S) score were recorded.

Results: Apply/Demand ratio in the group PR50 had a significant increase over the other groups $(\mathrm{P}<0.05)$. The incidence of excessive sedation and dizziness were significantly more frequent in the group PR50 $(\mathrm{P}<0.05)$. BIS and OAA/S score significantly decreased in the group PR25, PR50 at $15 \mathrm{~min}$ after the operation, the end of surgery (P < 0.05). At $5 \mathrm{~min}$ after the start of PCS, patients in the group PR25 and PR50 gave significantly less correct responses on the DSST than that of the group $\mathrm{P}(\mathrm{P}<0.05)$.

Conclusions: Compared with the propofol alone, intermittent bolus injection of propofol-remifentanil mixture could be used, appropriately, for the sedation and analgesia during MAC. The group PR25 in a low dose of remifentanil has more advantages in terms of sedation and satisfaction because of the group PR50's side effects. (Korean J Anesthesiol 2012; 63: 431-435)

Key Words: Monitored anesthesia care, Patient-controlled sedation, Propofol, Remifentanil.

\footnotetext{
Received: April 19, 2012. Revised: 1st, May 29, 2012; 2nd, June 1, 2012; 3rd, June 4, 2012; 4th, June 4, 2012; 5th, June 5, 2012. Accepted: June 11, 2012. Corresponding author: Jin Woo Choi, M.D., Ph.D., Department of Anesthesiology and Pain Medicine, The Catholic University of Korea, St. Vincent's Hospital, 93, Jungbudae-ro, Paldal-gu, Suwon 442-723, Korea. Tel: 82-31-249-7212, Fax: 82-31-258-4212, E-mail: cjwooo@catholic.ac.kr (c) This is an open-access article distributed under the terms of the Creative Commons Attribution Non-Commercial License (http:// creativecommons.org/licenses/by-nc/3.0/), which permits unrestricted non-commercial use, distribution, and reproduction in any medium, provided the original work is properly cited.
} 


\section{Introduction}

Monitored anesthesia care (MAC) usually involves the administration of intravenous adjuvants to produce sedation, anxiolysis, and amnesia, during minor diagnostic and therapeutic procedures or supplement analgesia, which is provided by the local or regional anesthetic techniques.

During monitored anesthesia procedures, patients are monitored to ensure their safety and comfort during the operation. With the optimum sedation technique, the chosen drug has sedative-hypnotic, anxiolytic, and amnestic properties; produces a low incidence of perioperative side effects (e.g., respiratory depression, nausea and vomiting); and provides the ease of titration to the desired level of sedation, while providing rapid return to a "clearheaded" state on the completion of the procedure [1]. Several drugs, such as barbiturates, benzodiazepine, ketamine, propofol, $\alpha_{2}$-agonist, nitrous oxide, opioids and non-opioid analgesics have been used for MAC, either alone or in combination $[2,3]$.

A specific form of MAC, patient-controlled sedation (PCS), may be an advantageous modality for local surgery, such as breast biopsy, which allows the patient to self-administer the exact amount of anesthetics required to treat varying degrees of pain and discomfort [4]. Remifentanil may have advantages over alfentanil because of its shorter half-life, comparative duration of effect to propofol, and lack of residual postoperative sedation [5].

Accordingly, we evaluated the dose-dependant efficacy of remifentanil, as an appropriate sedative drug, for MAC in the outpatient clinics undergoing breast biopsy surgery, which included a survey of the patients' satisfaction.

\section{Materials and Methods}

These were evaluated in 60 patients, who have been scheduled for elective surgical procedure, under a monitored anesthesia care. After an approval from the Institutional Review Board, written informed consent was obtained from all participating 75 patients who were scheduled for local breast biopsy, using PCS during the MAC, and who met the enrollment criteria. All patients were adult outpatients aged between 20 and 50 years, American Society of Anesthesiologists (ASA) classification I or II and scheduled for sequential breast biopsy surgery under the MAC. Preoperative exclusion criteria were pregnancy, kidney or hepatic disease, chronic medication with analgesic or sedative drug, history of alcohol or drug abuse and patients who could not understand the concept of PCS. Patients had fasted at least 8 hours before the operation, and did not receive any preoperative sedative drugs.

The patients were allocated to one of the three groups, which used a computer-generated sequence of random numbers. The patients respectively received an infusion of total $16 \mathrm{ml}$ solution that contained $10 \mathrm{ml}$ of $1 \%$ propofol $+5 \mathrm{ml}$ of saline + $1 \mathrm{ml}$ of $2 \%$ lidocaine (group P), $10 \mathrm{ml}$ of $1 \%$ propofol $+25 \mathrm{ug} / \mathrm{ml}$ of remifentanil $+1 \mathrm{ml}$ of $2 \%$ lidocaine (group PR25), $10 \mathrm{ml}$ of $1 \%$ propofol $+50 \mathrm{ug} / \mathrm{ml}$ of remifentanil $+1 \mathrm{ml}$ of $2 \%$ lidocaine (group PR50). PCS was delivered using a patient-controlled analgesia pump (Perfusor $\mathrm{fm}^{\mathrm{TM}}$, B. Braun, Germany) with 1 min lockout time. One milliliter of solution was delivered over $10 \mathrm{sec}$. The study pharmacist mixed all the medications immediately before the start of a breast biopsy surgery. In the propofol group, the solution contained $6.25 \mathrm{mg}$ of propofol per milliliter. In the Remifentanil-Propofol group, the solution contained, respectively, 7.81 ug (group PR25), 15.6 ug (group PR50) of remifentanil and $6.25 \mathrm{mg}$ propofol per milliliter.

The PCS medications were delivered by an infusion line, which was attached to the IV skin insertion site. All patients were provided with instructions on the use of the PCS system in the preoperative area.

Preoperatively, standardized psychological tests were performed by the patient. We used 10 visual analog scales (VAS) to determine the pretreatment level of anxiety $(0=$ calm to 10 = extremely anxious). A digit symbol substitution test (DSST) was used to assess the baseline level of cognitive function. The sedation level was also assessed by the investigator, using the observer's assessment of alertness/sedation (OAA/S) scale, with $1=$ wide-awake and alert to $5=$ asleep and/or unarousable, after completing the preoperative pain VAS, DSST, and OAA/S assessments. Deep sedation's evaluation is when OAA/S score change from 3 to 2 (responds only after mild prodding or shaking).

Before administration of the local anesthetic, and immediately after pump connection to a 22-gauge peripheral i.v. cannula, the patient was encouraged to make the first demand by pressing the hand-held triggering device, and in addition, to make a demand in the event of any discomfort or anxiety.

On arriving at the operating room, standard monitoring, including electrocardiography, non-invasive arterial pressure, respiration rate and peripheral pulse oximetry, was recorded. Oxygen was administered via nasal cannula at $3 \mathrm{~L} / \mathrm{min}$. Ephedrine $5 \mathrm{mg}$ was administered when systolic blood pressure (SBP) decreased below $90 \mathrm{mmHg}$ or $70 \%$ of the preoperative value. Atropine $0.5 \mathrm{mg}$ was injected to the patients when the heart rate (HR) fell below 40 beats/min. SBP, HR, respiratory rate ( $\mathrm{RR})$, and peripheral oxygen saturation ( $\mathrm{SpO} 2)$ were recorded at each time point, as follows; $\mathrm{B}=$ preoperative baseline, PCS $5=5 \mathrm{~min}$ after PCS start, Inc $=$ just after incision, OP15 = $15 \mathrm{~min}$ after incision, OPend = the end of surgery, R0 = just after arrival at recovery room, R15 $=15 \mathrm{~min}$ after at recovery room, and $\mathrm{R} 30=30 \mathrm{~min}$ after arrival at recovery. Moreover, the incidence of adverse events, including hypertension (SBP $>160$ 
$\mathrm{mmHg}$ ), hypotension (SBP $<80 \mathrm{mmHg}$ ), bradycardia (HR $<50$ beats/min), respiratory depression ( $R R<10$ breaths $/ \mathrm{min}$ ), and oxygen desaturation ( $\mathrm{SpO} 2<93 \%)$, were evaluated.

At the end of the surgery, the total amount of propofol and remifentanil administered was noted from the PCS display, as the A/D ratio (\%) were the number of self-administration attempts of the study drugs (demand), and the number of successful attempts (apply). Before discharge, from the day surgery unit, patients were asked their opinion of the sedation and its effect by using a $4-$ point rating scale $(1=$ highly satisfactory, 2 = satisfactory, 3 = somewhat satisfactory, 4 = unsatisfactory) [6].

Statistical analyses were performed, using GraphPad Prism (GraphPad Software, USA, 5.0). One-way ANOVA was used for the comparison among the groups in the following parameters: age, weight, height, ASA status, duration of sedation, operation time, volume of regimen requirements and $A / D$ ratio. The overall significance of the results was examined, using a twoway analysis of variance, and a Bonferroni post-hoc test was used for multiple comparisons. The Fisher's exact test was used to determine the incidence of adverse events. The results are expressed as the mean \pm SD or absolute number. $\mathrm{P}$ value of $<$ 0.05 was considered to be statistically significant.

\section{Results}

There were no differences among the three PCS groups, with respect to the demographic data (Table 1). Apply/Demand ratio $83 \%$ in the PR50 group had a significant increase over $64 \%$ in group P, 70\% in group PR25 $(\mathrm{P}<0.05)($ Table 1$)$. The incidence of deep sedation and dizziness were significantly more frequent $28 \%$, respectively, $32 \%$ in group PR50 patients than other groups $(\mathrm{P}<0.05)$ (Table 2). No episodes of respiratory depression or oxygen desaturation were observed in all the groups. No patient had intraoperative nausea, vomiting or pruritis.

Overall, patient PCS satisfaction was high in all three groups, after the surgery. However, $16 \%$ of patients in the PR50 group showed to be un-satisfactory. There were one case of hypotension (4\%) and bradycardia (4\%) in the PR50 group. BIS and OAA/S in the group PR25 significantly decreased at OP15 and OPend near the end of the surgery, respectively. BIS and OAA/ $\mathrm{S}$ score in the group PR50 significantly decreased during OP15 and OPend, respectively, near the end of the surgery $(\mathrm{P}<0.05)$ (Fig. 1). At 5 min after the start of PCS and before making the incision, patients in the group PR25 and PR50 gave significantly less correct responses on the DSST than those in the $\mathrm{P}$ group $(\mathrm{P}$ $<0.05$ )(Fig. 2).

\section{Discussion}

In this study, our results suggest that the propofol and low dose remifentanil mixture (group PR25) has more advantages than the high dose remifentanil (group PR50), in terms of side effects for MAC in outpatients who are undergoing breast biopsy surgery. These days, remifenanil has been used in short or long term sedation in the intensive care unit, sedation for various procedures, or as a supplementary drug, during general anesthesia.

Table 2. Side Effect Profiles for Three PCS Groups

\begin{tabular}{llcc}
\hline & $\begin{array}{c}\text { P group } \\
(\mathrm{n}=25)\end{array}$ & $\begin{array}{c}\text { PR25 group } \\
(\mathrm{n}=25)\end{array}$ & $\begin{array}{c}\text { PR50 group } \\
(\mathrm{n}=25)\end{array}$ \\
\hline Pain on injection & $3(12 \%)$ & $2(8 \%)$ & $2(8 \%)$ \\
Deep sedation & $0(0 \%)$ & $2(8 \%)$ & $7(28 \%)^{*}$ \\
Dizziness & $0(0 \%)$ & $0(0 \%)$ & $8(32 \%)^{*}$ \\
Un-satisfactory & $0(0 \%)$ & $1(4 \%)$ & $4(16 \%)^{*}$ \\
Hypotension (SBP $<80 \mathrm{mmHg})$ & $0(0 \%)$ & $0(0 \%)$ & $1(4 \%)$ \\
Bradycardia $(<50 \mathrm{rate} / \mathrm{min})$ & $0(0 \%)$ & $0(0 \%)$ & $1(4 \%)$ \\
\hline
\end{tabular}

Data are expressed as mean \pm SD. P group: propofol alone group, PR25 group propofol-remifentanil $(25 \mathrm{ug} / \mathrm{ml})$ group, PR50 group: propofol-remifentanil $(50 \mathrm{ug} / \mathrm{ml})$ group. Hypotension: SBP $<80$ mmHg or DBP $<50 \mathrm{mmHg}$ or $<30 \%$ level before drug injection. *P $<$ 0.05 , significantly different from other groups value.

Table 1. Demographic Data

\begin{tabular}{lccc}
\hline & P group $(\mathrm{n}=25)$ & PR25 group (n=25) & PR50 group (n=25) \\
\hline Age (yr) & $43.4 \pm 6.7$ & $37.3 \pm 3.6$ & $41.4 \pm 4.2$ \\
Weight (kg) & $63.7 \pm 8.8$ & $64.8 \pm 7.6$ & $58.8 \pm 9.9$ \\
ASA (I/II) & $23 / 2$ & $20 / 5$ & $22 / 3$ \\
Height (cm) & $156.2 \pm 6.3$ & $164.2 \pm 5.7$ & $161.2 \pm 5.2$ \\
Duration of sedation (min) & $25.1 \pm 11.8$ & $24.9 \pm 15.5$ & $26.2 \pm 23.6$ \\
Duration of operation (min) & $34.1 \pm 9.8$ & $37.5 \pm 12.4$ & $35.1 \pm 10.2$ \\
Volume of regimen requirements (ml) & $9.2 \pm 4.8$ & $8.2 \pm 5.5$ & $8.0 \pm 5.2$ \\
Propofol (mg) & $57.5 \pm 24.7$ & $51.3 \pm 25.2$ & $49.5 \pm 22.3$ \\
Remifentanil (ug) & N/A & $64.1 \pm 11.5$ & $124.1 \pm 19.7$ \\
A/D ratio (\%) & 64 & 70 & $83^{*}$ \\
\hline
\end{tabular}

Data are expressed as mean \pm SD. P group: propofol alone group, PR25 group: propofol-remifentanil (25 ug/ml) group, PR50 group: propofolremifentanil $(50 \mathrm{ug} / \mathrm{ml})$ group. A/D ratio: Apply/Demand ratio. ${ }^{*} \mathrm{P}<0.05$, significantly different from $\mathrm{P}$ group value alone. 

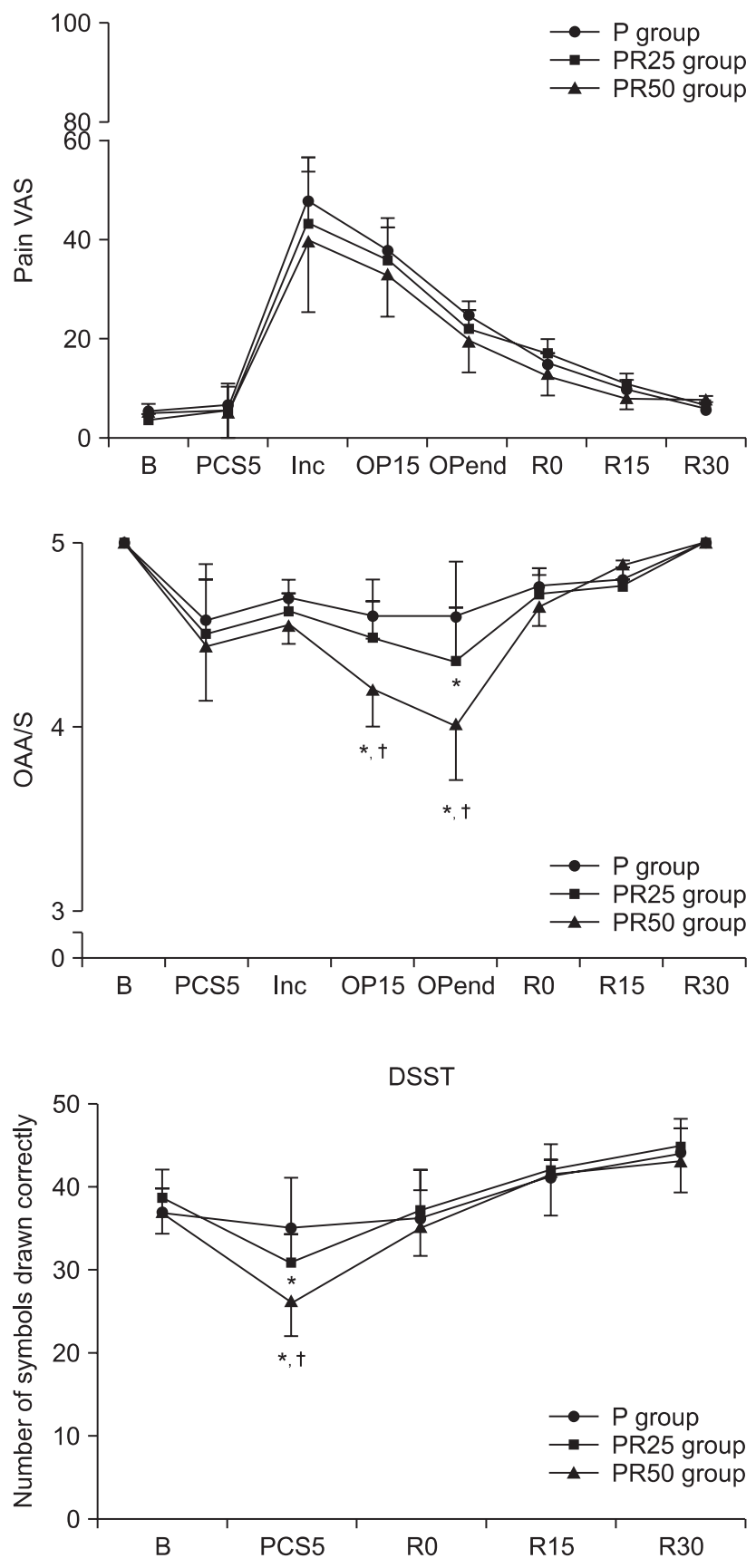

Fig. 2. The number of symbols correctly dawn on the digit symbol substitution test (DSST) for the three PCS group. P group: propofol alone group, PR25 group: propofol-remifentanil (25 ug/ml) group, PR50 group: propofol- remifentanil $(50 \mathrm{ug} / \mathrm{ml})$ group. B: baseline, PCS5: 5 min after PCS start, R0: just after arrival at recovery room, R15: 15 min after arrival at recovery room, R30: 30 min after arrival at recovery room. ${ }^{*} \mathrm{P}<0.05$, significantly different from $\mathrm{P}$ group value. ${ }^{\dagger} \mathrm{P}<0.05$, significantly different from other groups value. Data are expressed as mean $\pm \mathrm{SD}$.

Propofol has been the most widely used IV adjuvant during MAC, even though it lacks analgesic properties. Its sedation can also be supplemented by opioid analgesics to provide sedation-

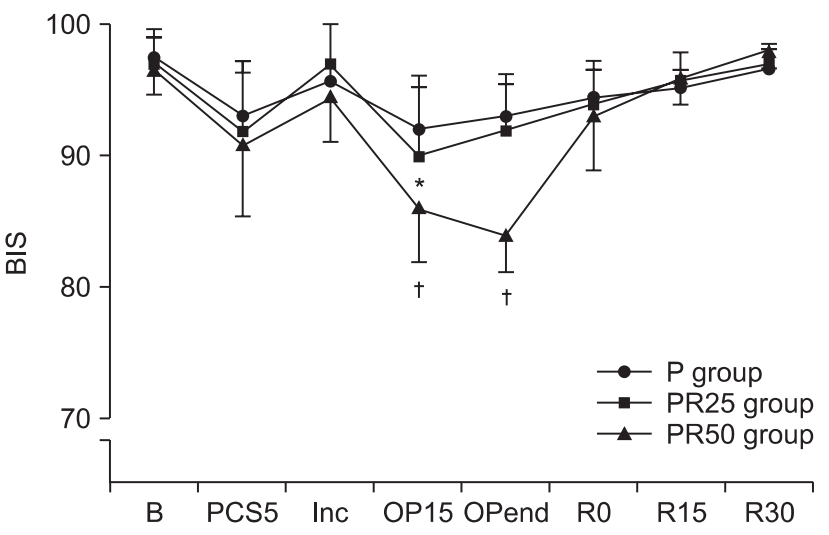

Fig. 1. Changes in pain visual analogue scale (VAS) scores, bispectral (BIS) values, observer assessment of alertness/sedation (OAA/S) scores for the three PCS group. P group: propofol alone group, PR25 group: propofol-remifentanil ( $25 \mathrm{ug} / \mathrm{ml}$ ) group, PR50 group: propofolremifentanil ( $50 \mathrm{ug} / \mathrm{ml}$ ) group. B: baseline, PCS5: 5 min after PCS start, Inc: just after incision, OP15: 15 min after incision, OPend: the end of surgery, R0: just after arrival at recovery room, R15: $15 \mathrm{~min}$ after arrival at recovery room, R30: $30 \mathrm{~min}$ after arrival at recovery room. $* \mathrm{P}<0.05$, significantly different from $\mathrm{P}$ group value alone. ${ }^{\dagger} \mathrm{P}<0.05$, significantly different from other groups value. Data are expressed as mean \pm SD.

analgesia for uncomfortable procedure performed without local anesthesia. It is capable of producing easily controllable levels of sedation, during a variety of procedures performed with or without supplemental local or regional anesthesia [1]. Joo et al. [4] have reported the efficacy of adding $5 \mathrm{mg}$ of propofol to 10 $\mathrm{ug} / \mathrm{ml}$ of remifentanil for PCS during a shock wave lithotripsy, which had a better overall satisfaction level than that of $10 \mathrm{ug} / \mathrm{ml}$ of remifentanil alone. PONV was decreased, patient satisfaction level was better, and there was a trend toward a decreased number of patients that required additional postoperative analgesics in the Remifentanil-Propofol group, compared with that of the Remifentanil group. This may have been caused by the sedating and remifentanil-sparing properties of propofol.

Moderate-to-large doses of remifentanil have been associated with acute opioid tolerance [7], PONV [8], and pruritus in the remifentanil-propofol group, compared with that of the remifentanil only group [9].

Opioid analgesics are often administered in combination with sedative-hypnotic agents to reduce pain, resulting from the injection of local anesthetic solutions and traction on deeper tissue structures. Although a combination of midazolam and fentanyl is very popular, this combination can produce adequate sedation and may be associated with undesirable side effects [10]. 
In a comparison of PCS by propofol and anesthesiologistadministered fentanyl-midazolam, the PCS group reported greater satisfaction and more rapid recovery of postoperative cognitive function [11].

Murdoch et al. [12] have reported that patient-maintained propofol sedation can be used effectively under a close clinical supervision by an anesthetist.

Choi et al. [13] have compared the sedation quality, side effects, and recovery profiles of propofol alone, propofol-fentanyl and propofol-ketamine, using PCS for breast biopsy procedures, using local anesthesia. This study has reported in contrast to the past studies of ketamine as an alternative to opioid adjuncts during propofol PCS, it has no more advantages than that of the supplemental fentanyl, in terms of sedation level and side effects.

Avramov and White [14] has reported administration of an intravenous anesthetic, propofol, in combination with an opioid infusion (i.e., alfentanil) to provide the sedation analgesia and amnesia with a low incidence of side effects, such as nausea and vomiting, in addition to respiratory depression in outpatients, who were premedicated with midazolam.

Unlike other sedatives, dexmedetomidine-induced sedation allows the patient to open their eyes to facilitate responses to verbal stimulation and communication, with patients showing normal cognitive abilities. Compared with propofol/alfentanil, dexmedetomidine reduced arterial pressure during the period of the operation. Satisfaction scores were also in favor of the patients that have been treated with dexmedetomidine [15].

In this study, the $\mathrm{A} / \mathrm{D}$ ratio was significantly higher in the group PR50 (83\%) than those in the group P (64\%) and group PR25 (70\%). That means that when the patient demands sedation or analgesia, lockout time is too short or the potency of primary bolus is high or more appropriate than the other groups. One minute of lockout time is the same in every group. Therefore, the potency of remifentanil in the group PR50 (potency), which had been compared to that of the other groups, are thought to be relatively high.

In conclusion, compared with the propofol alone, intermittent bolus injection of small doses of the propofol - remifentanil mixture could be used, appropriately, for the sedation and analgesia during MAC in local anesthesia. The group PR25 in a low dose of remifentanil has more advantage than the group PR50 in term of sedation and satisfaction because of the group PR50's deep sedation and dizziness in terms of side effects.

\section{Acknowledgments}

This study was supported by the Research Fund from the Research Institute of Medical Science, St Vincent's Hospital, and Suwon, Korea.

\section{References}

1. Smith I, White PF, Nathanson M, Gouldson R. Propofol. An update on its clinical use. Anesthesiology 1994; 81: 1005-43.

2. Cok OY, Ertan A, Bahadir M. Comparison of midazolam sedation with or without fentanyl in cataract surgery. Acta Anaesthesiol Belg 2008; 59: 27-32.

3. Celiker V, Basgul E, Sahin A, Uzun S, Bahadir B, Aypar U. Comparison of midazolam, propofol and fentanyl combinations for sedation and hemodynamic parameters in cataract extraction. Saudi Med J 2007; 28: 1198-203.

4. Joo HS, Perks WJ, Kataoka MT, Errett L, Pace K, Honey RJ. A comparison of patient-controlled sedation using either remifentanil or remifentanil-propofol for shock wave lithotripsy. Anesth Analg 2001; 93: 1227-32.

5. Sá Rêgo MM, Inagaki Y, White PF. Remifentanil administration during monitored anesthesia care: are intermittent boluses an effective alternative to a continuous infusion? Anesth Analg 1999; 88: 518-22.

6. Badrinath S, Avramov MN, Shadrick M, Witt TR, Ivankovich AD. The use of a ketamine-propofol combination during monitored anesthesia care. Anesth Analg 2000; 90: 858-62.

7. Guignard B, Bossard AE, Coste C, Sessler DI, Lebrault C, Alfonsi P, et al. Acute opioid tolerance: intraoperative remifentanil increases postoperative pain and morphine requirement. Anesthesiology 2000; 93: 409-17.

8. Bekker AY, Berklayd P, Osborn I, Bloom M, Yarmush J, Turndorf H. The recovery of cognitive function after remifentanil-nitrous oxide anesthesia is faster than after an isoflurane-nitrous oxide-fentanyl combination in elderly patients. Anesth Analg 2000; 91: 117-22.

9. Avramov MN, Smith I, White PF. Interactions between midazolam and remifentanil during monitored anesthesia care. Anesthesiology 1996; 85: 1283-9.

10. Bailey PL, Pace NL, Ashburn MA, Moll JW, East KA, Stanley TH. Frequent hypoxemia and apnea after sedation with midazolam and fentanyl. Anesthesiology 1990; 73: 826-30.

11. Osborne GA, Rudkin GE, Curtis NJ, Vickers D, Craker AJ. Intraoperative patient-controlled sedation. Comparison of patientcontrolled propofol with anaesthetist-administered midazolam and fentanyl. Anaesthesia 1991; 46: 553-6.

12. Murdoch JA, Grant SA, Kenny GN. Safety of patient-maintained propofol sedation using a target-controlled system in healthy volunteers. Br J Anaesth 2000; 85: 299-301.

13. Choi JW, Joo JD, In JH, Kim YS, Jeon YS, Ryu KH, et al. The comparison of sedation quality, side effects and recovery profiles of propofol alone, propofol-fentanyl and propofol-ketamine PCS for MAC. Korean J Anesthesiol 2006; 50: 428-33.

14. Avramov MN, White PF. Use of alfentanil and propofol for outpatient monitored anesthesia care: determining the optimal dosing regimen. Anesth Analg 1997; 85: 566-72.

15. Na HS, Song IA, Park HS, Hwang JW, Do SH, Kim CS. Dexmedetomidine is effective for monitored anesthesia care in outpatients undergoing cataract surgery. Korean J Anesthesiol 2011; 61: 453-9. 